\title{
DE AMOR E TRADUÇÃO: GUIMARÃES ROSA NAS RELAÇÕES COM SEUS TRADUTORES ${ }^{1}$
}

\author{
Mauricio Mendonça Cardozo e Maria Paula Frota
}

Para mim, era como se eu tivesse os mais amores!

(Rosa - Riobaldo)

Tomando por base a correspondência do escritor João Guimarães Rosa com seus tradutores Harriet de Onís (para o inglês), Edoardo Bizzarri (para o italiano) e Curt Meyer-Clason (para o alemão), este artigo tem em vista discutir alguns aspectos da dinâmica de construção do espaço de relação entre o autor e seus tradutores.

Como sabido, Rosa manteve com seus tradutores uma vasta correspondência, há muito referendada pela crítica como um material de inestimável potencial crítico. Uma das primeiras vozes a apontar para a riqueza desse corpus epistolar foi Paulo Rónai, a quem o escritor teria pessoalmente mostrado tais cartas. Em 1971, Rónai declararia:

O conjunto das respostas dadas aos tradutores alemão, italiano, francês, norteamericano e espanhol representa nada menos que uma exegese minuciosa da obra rosiana [...] não hesito em afirmar que a publicação conjunta de suas cartas a seus intérpretes daria vários volumes do maior interesse, um complemento indispensável da própria obra, um documento sem qualquer analogia não só em nossas letras, mas talvez em toda a literatura universal (apud Verlangieri 1993: 7).

Desde então, a crítica especializada, seja no campo dos Estudos Literários, seja no campo dos Estudos da Tradução, vem produzindo extensa fortuna crítica a partir desse material. No primeiro, a crítica literária soube aproveitar a correspondência como subsídio para a discussão de diversas questões pertinentes à poética roseana; no segundo, a maior parte da produção crítica é marcada por um interesse que se concentra basicamente em questões de recepção da obra de Rosa via tradução - no sentido do mapeamento e da discussão do impacto da tradução nos diferentes contextos de

\footnotetext{
${ }^{1}$ Nota do autor, a partir de uma nota da autora - este texto resulta de pelo menos duas experiências marcantes: de uma fala proferida pelo autor na XXVIII Semana do Tradutor, realizada na Unesp de São José do Rio Preto, em 2008; do diálogo sempre tão instigante e das tantas correspondências que marcaram o estágio de pós-doutoramento do autor na PUC-Rio, em 2009-2010, sempre no carinho da relação com a autora.
} 
recepção - e em questões teóricas de fundo - no sentido de se discutirem as concepções de tradução (do autor e de seus tradutores) que podem ser depreendidas das cartas. Poderiam ainda ser mencionados os trabalhos com foco em aspectos mais centralmente linguísticos da obra de Rosa, como, por exemplo, o estudo de seu léxico em geral, e da questão de seus neologismos, em particular.

Entretanto, nenhuma dessas questões será aqui examinada. Neste trabalho, a proposta é explorar, ainda embrionariamente, duas constatações que se configuraram ao longo de leituras e análises dos três conjuntos de cartas. Primeira, a de que a relação entre o escritor e seus tradutores não era meramente burocrática ou "diplomática" do ponto de vista do "registro" em que se construíam as relações, mas, sim, uma relação que indicava a construção de uma certa intimidade ao longo do período de correspondência. Segunda, a de que a relação entre o escritor e seus tradutores não era óbvia do ponto de vista das expectativas de relação entre um autor e seus tradutores. Daí o interesse em discutir formas distintas de construção das figuras do tradutor e do autor, em cada um dos casos, nesse espaço de relação instituído pela correspondência.

Rosa não parece comportar-se segundo os moldes de um autor autoritário, que se corresponde com um tradutor de quem exige um grau máximo de auto-apagamento. Ao contrário, as cartas sugerem uma dinâmica complexa de negociação do espaço de relação entre autor e tradutor. Daí o interesse em flagrar, nesse material, alguns aspectos da dinâmica de construção dessas relações.

É com essa perspectiva que, a partir deste ponto, pretendemos organizar nossas elucubrações em duas partes. Na primeira, procuraremos definir um pouco melhor os pressupostos teóricos de que nos valeremos, em especial no que diz respeito à centralidade da noção de relação, ao que estamos aqui chamando de "espaço de relação", e ao que isso tem a ver com o amor. Na segunda parte, faremos uma breve análise da correspondência entre Rosa e os três tradutores, tendo em vista esboçar traços que distinguiriam cada uma das relações, a partir dos quais serão levantadas algumas hipóteses, ilustradas com uma pequena mostra das cartas.

\section{Pressupostos: as noções de relação, tradução, correspondência e amor}

A noção de relação ocupa um lugar central nesta reflexão, uma vez que ela constitui o princípio articulador do entendimento das demais noções aqui em foco, as de tradução, de correspondência e de amor. 
Articuladas, relação e tradução parecem constituir um caminho de reflexão que é percorrido por muitos desde a Antiguidade: entendemos que, de maneira implícita, a noção de relação sempre foi, em alguma medida, subsidiária das reflexões sobre tradução, seja na formulação de discursos voltados para a diferença entre a escrita autoral e a tradutória, as línguas e culturas de partida e de chegada etc., seja na daqueles discursos voltados para a identidade entre tais objetos.

Por muito tempo, o pensamento dominante sobre tradução se fundou numa dimensão mais retórica, voltando seu foco ora para a discussão do impacto de questões estéticas na relação com o ouvinte e com o leitor, ora para a discussão do modo de articulação da relação de fidelidade com o texto original (se pela prevalência da letra ou do espírito). Contudo, pelo menos desde Herder (um dos pensadores mais fundamentais para a compreensão da tradução no contexto do romantismo alemão) e Schleiermacher, uma outra percepção da prática de tradução se somaria ao seu valor retórico. Trata-se da idéia de que a prática de tradução é também instrumento de uma prática de relação que, mesmo fundada na dimensão linguística, textual e discursiva, transcende essas dimensões; ou seja, trata-se da idéia de que a tradução é uma prática humana que dispõe sujeitos, línguas, culturas e textos em relação.

Ora, de algum modo, pensar tradução a partir da noção de relação poderia nos parecer algo quase óbvio, mas os problemas começam a surgir quando olhamos essa noção de relação mais de perto, quando se tem em vista que os sujeitos em relação não são mônadas fechadas, definidas e estanques, mas, sim, formações extremamente complexas. E o são, por vários fatores: (i) por constituírem e, ao mesmo tempo, serem constituídos, ou sobredeterminados, como diria Freud, a partir de diferentes ordens de relação: individual e social, cultural e linguística, econômica e ideológica, entre outras; (ii) por essas ordens de relação estarem imbricadas segundo princípios que estão longe de serem simples, lineares, previsíveis, ou mesmo de seguirem uma lógica evidente de causa e efeito; e (iii) por essas relações não serem estanques mas, sim, dinâmicas, no sentido de se reconstruírem incessantemente, instaurando uma tensão constante entre permanência e inovação no espaço da experiência individual e coletiva, da memória e da história, dos costumes e da tradição.

Os problemas surgem quando se tem em vista também que as línguas e culturas em relação não são constructos estanques, com limites nítidos, mas espaços instaurados e habitados pelo homem em sua condição humana. Nesse sentido, e buscando situar esta problemática fora do terreno de obviedade que a princípio ela possa sugerir, cabe 
sublinhar que línguas e culturas são espaços de relação da mesma ordem da complexidade do sujeito, e que, portanto, são espaços relacionais que só têm valor como unidade (como UMA determinada língua ou UMA determinada cultura) se assumirmos, nessa circunscrição de unidade, uma vagueza ou flexibilidade que lhe é inerente.

Os problemas surgem quando se tem em vista ainda que os textos em relação, sendo objeto de uma prática humana, instituem também, eles mesmos, espaços relacionais. Ou seja, que apesar de nos referirmos às obras e aos textos como unidades fechadas e operarmos cotidianamente com essas circunscrições, os textos, no sentido mesmo da metáfora que o termo carrega (como tecido, tessitura), são, eles mesmos, constituídos a partir de um complexo de relações, o que significaria dizer que a relação entre textos é, ela própria, antes de mais nada, uma relação entre relações.

Enfim, os problemas surgem quando passamos a levar em consideração que a relação não é um fenômeno espontâneo, imediato ou automático; tampouco é um elemento estanque e neutro de articulação que se dê de pronto a partir da simples justaposição das partes, dos termos; ao contrário, a relação, em toda a sua complexidade, é sempre algo por vir, algo por se instituir, algo em constante construção. E, além disso, é na relação que as partes, que os termos da relação se constituem, ou, ao menos, se reconhecem enquanto partes num mesmo espaço de relação.

É nesse sentido que o movimento de articulação de um pensamento sobre tradução a partir da noção de relação parece não poder se eximir de discutir e problematizar a própria noção de relação. Mas lembremo-nos daquilo que nos traz a toda essa reflexão e que, portanto, faz deste texto um lugar paralelo àqueles em que tentamos aprofundá-la (veja-se, por exemplo, Cardozo 2009, 2008). O importante aqui é pensar que, no contexto das correspondências de Rosa, a prática de tradução, entendida na complexidade de sua natureza relacional, é mais do que o simples assunto dessas tantas cartas: antes, é objeto de desejo tanto de um sujeito-autor quanto de outros três sujeitos-tradutores que se põem em relação.

Passemos agora a articular relação e correspondência.

Para Antoine Berman, a noção de relação é central e fundadora de uma compreensão ética da tradução, ao ponto de afirmar, no texto "A tradução em manifesto", que a tradução "é relação, ou não é nada" (Berman 2002: 17). Curiosamente, em Pour une critique des traductions (1995), Berman se serve justamente da figura da correspondência como metáfora para destacar a centralidade da componente relacional na prática de tradução. Não apenas no sentido de uma 
equivalência, da expressão de uma relação que equaciona original e tradução, como quando dizemos que a tradução corresponde ao original. Mas também no sentido mesmo epistolar, como um "faire oeuvre-en-correspondence" (p.94), assumindo, portanto, toda a densidade desse termo: como uma prática que constrói uma relação e, ao mesmo tempo, performa, numa dimensão quase narrativa, a construção dessa relação; como uma prática que instaura um espaço de diálogo, de convivência entre os envolvidos. É como se pudéssemos dizer que a tradução se corresponde com o texto de partida, que, a cada instante de seu gesto tradutório, o tradutor se corresponde com o autor, e assim por diante.

Ora, se podemos entender, com Berman, que a tradução é uma produção textual “em correspondência”, a correspondência (no sentido da troca de cartas) que se organiza em meio a circunstâncias reais de práticas de tradução parece potencializar ainda mais essa dimensão relacional. Em outras palavras, poderíamos dizer que a correspondência entre Rosa e cada um de seus tradutores performa um longo processo de construção de uma relação entre dois sujeitos, autor e tradutor, motivada pela discussão de um longo processo de construção de uma relação entre dois textos, duas línguas, duas culturas.

Para essa rede de articulações que nos vem guiando queremos neste ponto, aos poucos, trazer a noção de amor.

É em vista dessa rede conceitual que podemos ler nosso corpus epistolar como uma espécie de dramatização do processo de construção de um espaço de relação. E ao longo desse processo, não é apenas o espaço da correspondência e do diálogo que se instaura; ao longo desse processo, os próprios sujeitos da relação vão se construindo como sujeitos, vão construindo o modo como se dispõem na relação com o outro, o modo como, nesse espaço, se escrevem.

Se a relação de Rosa com seus tradutores fosse uma relação meramente burocrática, diplomática, formal e distanciada, não haveria a nosso ver muito interesse em tentar flagrar o modo como cada uma das partes vai se inscrevendo, aos poucos, nesse espaço e construindo-se como sujeito-da-relação. Poderíamos supor que esse processo não traria grandes surpresas; mas, como já dito, não é isso o que ocorre. Em primeiro lugar, porque, paralelamente às suas atividades profissionais (como funcionário público do corpo diplomático) e à continuidade de escritura de novos textos de criação, Rosa faz questão de manter intensa e extensa correspondência com seus tradutores, o que sinaliza uma grande disposição para a construção dessas relações. Em segundo lugar, porque os três conjuntos de cartas nos mostram como tanto Rosa quanto 
seus tradutores acabam promovendo um movimento ora de aproximação, ora de distanciamento, estruturado a partir da construção de uma certa cumplicidade e de um grau de intimidade que variam ao longo do período em que se correspondem. Portanto, Rosa não se escreve sempre do mesmo modo nesse espaço, nem os tradutores assumem sempre o mesmo lugar. Além disso, contrariamente ao que o senso comum esperaria, não identificamos uma voz autoral inabalável, que dita verdades aos seus tradutores, um AUTOR MAIÚSCULO, nem vozes unissonamente submissas de tradutores minúsculos, de sujeitos carentes de uma voz autoral.

Em alguma medida, para quem a expectativa de leitura dessas correspondências consiste apenas em encontrar uma definição clara e bem delineada, exemplar de uma relação bem demarcada entre tradutor e autor, pode-se dizer que essas cartas não são muito representativas, frustram mesmo tal expectativa. Isso simplesmente porque nas relações que ali se constroem são raros os momentos em que Rosa assume explicitamente uma voz autoritária, de Autor maiúsculo, e em que os tradutores, em resposta, num suposto abrigo minúsculo de sua voz, assumem um lugar de submissão. O que se mostra dominante ao longo das cartas é um jogo constante de inversão ou dissimulação da posição de poder, que é assumida tanto pelo autor quanto pelos tradutores. Não se quer dizer com isso que esse poder não seja negociado, disputado; que as instâncias de autor e tradutor se confundam e se diluam completamente. Não é isso. O que há é que o jogo é mais complexo. O que é dominante, ao longo das correspondências, é uma dinâmica de relação que passa por momentos de sedução, de conhecimento, de convivência, de gozo, de separação e de saudade.

É nesse sentido que a construção da relação, dramatizada no conjunto das cartas, parece encenar os vários movimentos de uma relação amorosa: de uma relação que, de tradutor para tradutor, varia de timbre, modulada entre os vários matizes do amor e da paixão; e de uma relação que, no percurso de sua própria construção, varia também de amplitude ao longo do período, numa dinâmica belamente retratada pelo próprio Rosa em uma passagem do Grande Sertão: Veredas, em que a voz de Riobaldo, rememorando o encontro com Reinaldo, diz:

sempre que se começa a ter amor a alguém, no ramerrão, o amor pega e cresce é porque, de certo jeito, a gente quer que isso seja, e vai, na idéia, querendo e ajudando; mas, quando é destino dado, maior que o miúdo, a gente ama inteiriço fatal, carecendo de querer, e é um só facear com as surpresas. Amor desse, cresce primeiro; brota é depois. (Rosa 1986: 118) 
Para efeito das hipóteses que a seguir serão levantadas, faremos uma breve referência a alguns matizes do amor e da paixão com base nos termos discutidos por Frota (2000). Nesse livro, a partir de Freud e de Lacan, pretendeu-se dar prosseguimento ao pioneirismo de Silveira Jr., psicanalista e tradutor brasileiro que, em A tradução - dados para uma abordagem psicanalítica (1983), faz uma analogia entre a relação sexual - noção lacaniana que nomeia a relação que se quer fusão, encontro perfeito e completo de dois indivíduos - e a relação tradutória tal como majoritariamente prevista por tradutores e teóricos da tradução. O autor argumenta que ambas as relações são marcadas pelo desejo de que "o dois se faça um", e propõe que a relação experimentada pelos tradutores passe a ser concebida como uma relação de amor, já que nesta está implicado o discernível e o assimétrico, o um da pluralidade e não o Um totalizante.

Freud, ao tratar da relação de transferência como uma relação de amor, já fizera essa distinção entre os dois tipos básicos de relação, referindo-se a uma como amor feliz e à outra, àquela que o senso comum denomina "paixão", como amor infeliz. A primeira, que Lacan chamará de "amor dom ativo de si", visaria sempre a particularidade do sujeito amado e se construiria como relação possível justamente porque visa o outro em sua diferença, constituindo uma relação em que há necessariamente (e no mínimo) dois, em que há a necessidade de uma reciprocidade, e não a tentativa inalcançável de que haja uma totalidade, fusão e portanto apagamento; uma relação, enfim, em que o outro não está apenas a serviço de saciar as demandas de um EU (o ego, o moi imaginário), mas, antes, uma relação marcada pela suplementaridade no sentido de marcada pela dimensão do real, da falta que apenas muito provisoriamente se tem a sensação de tamponar.

A relação sexual é marcada pela demanda de uma complementaridade, pelo afã de saciar com o outro uma falta que não se sacia não por incompetência, mas por ser insaciável (a completude "não pára de não se escrever", diz Lacan) - exceto, como já indicado, por uns breves momentos (aqueles em que a falta real cede lugar ao Um, que “pára de não se escrever”). Cai-se na relação sexual quando se imagina que o todo passageiro deve ou pode ser permanente (que ele "não pararia de se escrever"). Como diz o ensinamento lacaniano, para além (ou aquém) do sentido corriqueiro da expressão, a relação sexual não existe. Imaginária, essa relação apresenta nuances em função da modalidade de projeção do objeto idealizado, podendo construir-se ou a partir de uma projeção acentuadamente narcísica do EU sobre o outro, que interdita o outro na 
relação, produzindo o seu apagamento; ou, ao contrário, a partir de uma idealização do OUTRO que produz um esvaziamento libidinal do eu.

Essas categorias serão referidas mais adiante. Passemos agora, finalmente, às correspondências.

\section{A correspondência de Rosa com Onís, Bizzarri e Meyer-Clason: fragmentos de três discursos amorosos}

As correspondências de Rosa com a norte-americana Harriet de Onís, com o alemão Curt Meyer-Clason e com o italiano Edoardo Bizzarri constituem os três maiores compêndios epistolares da obra do escritor.

A correspondência com a tradutora é a que integra o maior número de documentos: são ao todo 128 cartas, trocadas ao longo de quase oito anos - de novembro de 1958 a outubro de 1966. Essa correspondência não foi publicada na íntegra, mas há uma dissertação intitulada Guimarães Rosa - correspondência inédita com a tradutora norte-americana Harriet de Onís, defendida em 1993 por Iná Valéria Rodrigues Verlangieri, que apresenta, organiza e anota exaustivamente todo o conjunto de cartas.

A correspondência com o tradutor alemão (Rosa 2003a) é a segunda maior e é a que se prolonga por mais tempo: são ao todo 73 cartas, trocadas durante quase dez anos — de janeiro de 1958 a agosto de 1967. Essa correspondência só ganharia sua primeira edição integral em 2003.

Já a correspondência com o tradutor italiano (Rosa 2003b) é a terceira maior: são 59 cartas, trocadas, como no caso daquela com a americana, ao longo de quase oito anos — de outubro de 1959 a agosto de 1967. Essa correspondência seria a primeira a ser publicada, já em 1972.

A periodicidade com que Rosa e seus tradutores respondiam às cartas é bastante irregular, constituindo intervalos que podem variar de algumas poucas semanas a mais de um ano. Também a extensão das cartas é variável, indo desde um bilhete até cartas acompanhadas por páginas e páginas de anexos, com glossários, comentários das traduções e novas sugestões de tradução.

Rosa inicia uma prática mais constante de correspondência com esses três tradutores aproximadamente na mesma época, entre 1958 e 1959, o que coincide com o momento em que começa a sofrer de maneira crônica alguns problemas sérios de saúde. Curiosamente (ou, ao contrário, talvez por esse motivo mesmo), o escritor, ao longo de 
sua última década de vida, manteria correspondência com diversos tradutores. Ao lado dos três que temos aqui em foco, Rosa ainda trocaria cartas regularmente com o tradutor francês Jean Jacques Villard, entre 1961 e 1967; com os tradutores para a língua espanhola Ángel Crespo e Pilar Bedate, entre 1964 e 1967; além de uma correspondência mais esparsa com tradutores para outras línguas (como o sueco, por exemplo). Considerando que Guimarães Rosa faleceria (ou, roseanamente falando, “ficaria encantado") em novembro de 1967, podemos pensar que as relações construídas pelo autor com seus tradutores só encontraria um fim por ocasião de sua morte.

Tendo em vista o imenso volume de cartas, ensaiamos uma abordagem mais econômica desse corpus. Será aqui desenvolvida uma leitura das relações de Rosa com seus três tradutores a partir de um traço muito específico: a forma como o escritor ou cada um dos tradutores refere-se, na abertura de cada carta, ao seu interlocutor direto; ou seja, a forma de tratamento utilizada nas cartas como indício de uma certa disposição ao outro. É certo que a manutenção de um registro formal ou informal, apenas por força de convenção, pode produzir enormes apagamentos de uma eventual manifestação da disposição do sujeito para uma relação menos ou mais formal; mas, por outro lado, a variação da modalidade de tratamento, sobretudo quando na direção do formal para o informal, pode, eventualmente, sinalizar no enunciador uma disposição de aproximação de seu interlocutor. Em outras palavras: sem ignorar o que se apaga da relação no convencionalismo das formas de tratamento, esta tentativa de abordagem dos três conjuntos de correspondência tem em vista flagrar pequenas nuances de modalização em torno da convenção e atribuir a elas possíveis significados.

Favoravelmente à riqueza que se pode enxergar em tais formas, cabe argumentar, com Freud, que nessa escrita epistolar, como em qualquer outra expressão de linguagem, está implicado o inconsciente, ou seja, essas formas de endereçamento ao outro podem, em maior ou menor grau, trazer sintomas de desejo, do desejo do inconsciente, do Outro. A escolha por uma forma, dentre as incontáveis formas que a língua em sua flexibilidade nos propicia, normalmente se dá, ainda que nem sempre por completo, à nossa revelia - isso $(E s, i d)$ é certo. Como aprendemos com a psicanálise, o inconsciente não deixa nenhuma de nossas ações fora de seu alcance.

Sempre que possível, o traço que aqui se busca, traço de variação da forma de tratamento, será articulado com outros elementos característicos de cada corpus de correspondência, para que, em conjunto, possam dar maior sustentação a esta leitura. 
$\mathrm{Na}$ correspondência com a tradutora americana, a relação se construiria a partir das cartas sempre em inglês de Harriet de Onís, que fazia questão de explicitar o seu domínio restrito da língua portuguesa, às quais Rosa responderia sistematicamente em português, declarando, de sua parte, uma falta total de domínio da língua inglesa. Provavelmente por conta dessa limitação linguística, a relação entre Onís e Rosa seria povoada também por outros colaboradores. A tradutora, a quem Rosa passaria a chamar de Madrinha, manterá, no texto de suas cartas, um registro relativamente constante ao longo de toda a correspondência, marcado por uma certa informalidade. Disso dão testemunho as poucas variações da modalidade de tratamento usada por Onís nas saudações: sua primeira carta saúda Rosa com um My dear Mr. Guimarães Rosa, que logo se transforma em Dear Mr. Guimarães Rosa e mantém-se assim até sua última carta, com exceção de uma única, em que ela se vale de um Dear Friend. O escritor, por sua vez, saúda a tradutora, em sua primeira carta, com um Mui prezada Senhora, passando depois a alternar, durante bons anos, entre Cara Senhora de Onís e Prezada Senhora de Onís, e passando, mais adiante, a permitir-se algumas variações um pouco mais informais, e aparentemente amorosas, como Minha grande e muito Amiga ou Minha boa e grande amiga Mrs. de Onís, que culminariam, em sua última carta, na fórmula mais calorosa, Querida Mrs. de Onís.

Já na correspondência com o tradutor alemão, a relação com a língua seria um pouco diferente. Ao longo dos primeiros anos, Meyer-Clason escreveria suas cartas em português, mas de 1963 em diante, passaria a escrever sistematicamente em alemão; Rosa admitiria ser um leitor de língua alemã, mas incapaz de escrever uma linha sequer. De todos os conjuntos de cartas, é neste que percebemos uma maior variação nas formas de endereçamento ao outro, durante todo o período. A primeira carta escrita por MeyerClason saúda Rosa com um Excelentíssimo Senhor Ministro, que, com o passar do tempo, se transforma em Prezado Senhor Guimarães Rosa, vai se modificando num Prezado amigo e Senhor Guimarães Rosa, num Caro Senhor, Caro e estimado Senhor e, depois, num Caro amigo Guimarães Rosa, para, somente em 1966, após oito anos de correspondência, transformar-se num Meu caro mestre e suas pequenas variações, como Meu caro mestre e mago, Caro amigo e mestre e Caro mestre. Já o escritor saudará o tradutor em sua primeira carta com um Prezado Senhor Curt Meyer-Clason, passando logo para um Meu caro Curt Meyer-Clason e mantendo-se, até a última carta, fiel à formulação Meu caro Meyer-Clason, sem demonstrar qualquer variação de tratamento, 
mesmo a partir do momento em que o tradutor começa a dirigir-se ao escritor como "mestre e amigo".

No caso da correspondência com o tradutor italiano, que morava em São Paulo, as cartas eram todas escritas em português, de ambas as partes. Para além do fato de construírem toda a relação numa mesma língua, é interessante perceber uma variação paulatina na linguagem das cartas de Bizzarri, que, à medida que o tempo passava, começaria a mimetizar, em algumas passagens de suas cartas, uma espécie de idioleto roseano. Dentre os três conjuntos de cartas, é este que apresenta a menor variação na forma de tratamento: diferentemente dos outros casos, Bizzarri usará, da primeira à última carta, a mesma forma de tratamento: Meu caro Guimarães Rosa. Já Rosa saúda o tradutor inicialmente com Meu caro Professor Edoardo Bizzarri, variando, na segunda carta, quando escreve Meu caro Edoardo Bizzarri, para, logo depois, assumir um definitivo Meu caro Bizzarri.

Se, articulado a outros aspectos da correspondência, o padrão de variação da modalidade de tratamento nas cartas pode ser lido, em cada um dos casos, como indício da especificidade de cada relação entre tradutor e autor, talvez possamos, com base nesses diferentes padrões, fazer algumas perguntas e levantar algumas hipóteses.

\section{Rosa e Onís}

...aceito, mas com pena...

(Rosa)

No caso da correspondência com a tradutora americana, se poderia perguntar o que indicaria o fato de que, ao longo de todo o período, a tradutora teria um padrão de variação da modalidade de tratamento menor do que o de Rosa, que, mesmo mantendose num registro informal moderado, arriscaria, vez ou outra, avançar um grau a mais na escala da intimidade, insistindo em referir-se a Onís como Amiga?

É possível que esse padrão de variação seja sintomático de dois traços característicos da relação da tradutora com Rosa. Primeiro, o de que Onís manifestava uma certa teimosia, recorrente, na maior parte dos casos de negociação de soluções de tradução, simplesmente ignorando muitos dos pedidos de Rosa. Este costumava insistir em alguns poucos pontos, mas fazia abertamente uma série de concessões, parecendo tolerar as toleimas da tradutora, sempre com a justificativa de que não era bom sabedor do idioma inglês. O segundo traço, o de que Onís deixa claro que se considerava uma 
descobridora de talentos e que Rosa teria sido uma de suas maiores descobertas. Rosa, na relação direta com a tradutora, reagiria muito gentilmente a essa manifestação, atribuindo-lhe o epíteto de Madrinha e pedindo-lhe que estendesse o amadrinhamento ao menino Miguilim. No entanto, os traços desse comportamento, somados, talvez tenham contribuído para que o escritor, nas correspondências mantidas com Bizzarri e Meyer-Clason, passasse a referir-se à tradução americana como relativamente precária, quando não como um malogro.

Cabe aqui um destaque, que parece reforçar a relevância dessa manifestação crítica indireta do escritor: ainda que estivesse longe de ser um autor condescendente, ainda que sempre propusesse novas soluções para os esboços de tradução e ainda que não poupasse um esforço crítico severo com todos os seus tradutores, Rosa assumiria como procedimento padrão em todas essas relações, independentemente do volume e da dimensão dos reparos propostos, um exercício constante de elogio ao outro, louvando invariavelmente o tradutor com quem se correspondia como "o melhor, o insuperável, o definitivo". Sendo assim, o elogio hiperbólico, padrão retórico desses seus relacionamentos, talvez não deva ser considerado um traço muito relevante para a reconstrução da avaliação que o escritor de fato fazia das traduções de suas obras. Por outro lado, no caso único da tradução americana de Harriet de Onís, Rosa faria referências negativas a esse trabalho, o que - na contramão da sua reiterada lógica do elogio - talvez possa ser indicativo de uma real insatisfação: seja com a relação construída com a tradutora, seja com o produto dessa relação, a tradução.

Nesse sentido, podemos pensar que na relação que Onís imaginariamente constroi com Rosa predomina o "amor-paixão", aquela modalidade de relação em que o eu, um EU maiúsculo, se projeta narcisicamente sobre o outro, não permitindo que este se manifeste enquanto tal. Já Rosa em direção a ela parece disposto a construir uma relação amorosa nos termos do que a reflexão lacaniana sobre o amor denomina "amor dom ativo de si", o amor possível, que procura conviver com a impossibilidade de saciar a falta. Ainda assim, essa disposição parece frustrar-se dada a não reciprocidade, fundada, a nosso ver, numa certa distância e impermeabilidade de Onís em relação a Rosa, provável consequência do fato de que, em sua projeção narcísica, a tradutora não conseguiria promover uma maior aproximação do escritor, uma maior aceitação das suas diferenças. ${ }^{2}$

\footnotetext{
${ }^{2}$ Não nos escapa a possibilidade de se somar a essa interpretação apresentada, segundo a qual a tradutora se posiciona como um EGO que não endereça ao outro sua energia libidinal, uma outra interpretação, a
} 
Vejamos alguns excertos que julgamos ilustrar certos aspectos dessa relação, todos eles extraídos de cartas datadas de 1959:

Rosa, 15 de janeiro: "é realmente para mim uma grande satisfação este nosso cordial encontro e conhecimento, em tão simpáticas circunstâncias, que prometem uma camaradagem intelectual firme e duradoura." (Verlangieri 1993: 58)

Onis, 6 de março: "Alas, you may find many errors in my version [do conto Duelo], but I don't think they will be quite the same kind as in Augusto Matraga. Eduardo Mallea [escritor argentino] once wrote an article about me in which he called me 'la traductora de la intuicion'. I am afraid that sometimes I draw too freely on my intuition." (Verlangieri 1993: 67)

Rosa, 2 de abril: "Vou estudá-la, a tradução, com o maior carinho e cuidado, e penso poder enviar-lhe dentro destes dez dias o resultado, em algumas anotações. Não sei até que ponto elas irão servir-lhe, mas, naturalmente, vou consagrar-lhes meu máximo esforço de boa-vontade e alegria de cooperação.” (Verlangieri 1993: 71)

Rosa, 8 de abril: "Em adiantamento ao meu bilhete interlocutório de 2 deste mês, só hoje é que respondo, propriamente, à sua estimada carta de 15 de março último. E vão, em anexo, ao mesmo tempo, as anotações que me foi possível fazer à margem de sua magnífica tradução. [...] Sua tradução está realmente esplendida. E, creia-me, nisto não entra gota de lisonja convencional ou de entusiasmo irrefletido, e sim, clara sinceridade. [...] Agora, algumas explicações sobre as observações que alinhei. Umas NOTAS sobre as 'NOTAS', A Amiga verá que me atirei a redigi-las com ardor e afinco; e me perdoará, também, se, em vários pontos, e não obstante a boa-vontade, elas comparecerão mais como elemento perturbador e de estorvo do que como auxílio. De fato, achei mais aconselhável, num caso destes, botar no papel tudo o que me passava pela cabeça, e que, pelo menos como rumo de indicação, the pudesse vira ser útil. Nas soluções apontadas, assim, não recuei ante o atrevimento de apresentar formas rebarbativas ou absurdas, e mesmo impossíveis, macaqueando, numa espécie de caricatura de inglês, coisas de fazer arrepiar os cabelos aos sabedores do idioma. Repito, foi de propósito. Em tais casos, meu único intuito é sugerir rumos, acenar com pistas, certo de que a Amiga, 'pela idéia ou pela toada', saberá achar o que eu não poderia saber. Estaremos, muitas vezes, obrigados a um tateio de mãos, de olhos fechados e bocas mudas, como se no diálogo de duas Helen Keller. Mas, a confiança em sua sensibilidade e capacidade já são muito grandes." (Verlangieri 1993: 72-73)

Onis, 10 de abril: "I am awaiting with the greatest interest your comments and criticism of 'Duelo'. I am sure you will find many things that need revision; but I think you may like parts of it." (Verlangieri 1993: 81)

Rosa, 15 de abril: "Estou recebendo, neste momento, sua carta de 10 do corrente [...]. E, creia, estou-lhe cada vez mais grato, gratíssimo. Por seu gracioso intermédio, por tão simpático entusiasmo e admiráveis esforços, é que a minha modesta obra terá tão auspiciosa entrada no mundo de língua inglesa - vale dizer: no vasto Mundo. Posso chamá-la de Minha Madrinha. E que madrinha!” (Verlangieri 1993: 82)

qual explicaria o movimento narcísico que atribuímos a Onís como resultado de uma forte insegurança, gerada justamente pelo movimento inverso, o investimento, no OUTRO, de toda a sua libido, ficando ela assim esvaziada de amor, insegura em seu apaixonamento, daí necessitando eliminar o Sujeito responsável por tal estado de coisas e reverter a situação. 
Onis, 20 de abril: "I have just received your letter of the 15th, and the copy of 'Duelo'. [...] You have no need to feel grateful to me, though it is very nice to know that you are pleased with what I have done. [...] And if I am your 'madrinha', I have picked myself a fine 'ahijado'."' (Verlangieri 1993: 87)

Onís, 15 de maio: [Nesta carta, constata-se que das 23 alterações que Rosa propusera, Onís aceita 8 e propõe outras soluções para as restantes; no entanto, em nota à edição da correspondência, Verlangieri (1993: 109-112), após o cotejo com a versão publicada do conto, constata que a tradutora manteria, na publicação final, suas versões anteriores, a despeito de, nessa carta, dizer aceitar as sugestões do escritor.]

Rosa, 21 de maio: "Gratíssimo pelo cordial e amável interesse sempre demonstrado pela bondosa Amiga. Sobre os 'pontos' da Tradução, penso que, graças à sua infinita boavontade, fizemos longo avanço, que pode ser considerado definitivo. Apenas, para não perder a oportunidade, comentarei ainda os seguintes: [Rosa insiste em 6 pontos, aos quais se refere com expressões como 'aceito, mas com pena', 'quem sabe, então, ficaria melhor', e encerra a carta dizendo...] Assim, pois, celebremos o final acordo. Não é necessário que me envie mais contrapropostas, deixo o resto ao seu critério de escolha." (Verlangieri 1993, p.113-114)

\section{Rosa e Meyer-Clason}

Só com amor, sei, é que uma tarefa dessa se faz.

(Rosa)

Passemos agora à correspondência de Rosa com o tradutor alemão: o que indicaria o contraste entre uma imensa variação na modalidade de tratamento por parte de Meyer-Clason e uma variação mínima por parte de Rosa? Não apenas a partir dessa questão, mas, também, de outros traços das cartas, é possível interpretar que na relação que se constroi a partir de Meyer-Clason em direção a Rosa predomine o "amorpaixão", como naquela construída por Onís, mas, nesse caso, às avessas. Ou seja, dando-se a ver mais tipicamente como uma idealização do outro, com a qual este é promovido à condição de OUTRO, produzindo um esvaziamento de si mesmo e da sua condição de sujeito. Nesse sentido, diríamos que o alemão é esvaziado de sua própria energia amorosa e passa a ocupar uma posição de submissão, verbalizada, por exemplo, pela referência a Rosa como Mestre.

Já a relação que se constroi a partir de Rosa em direção a Meyer-Clason, parece, ela também, sugerir uma disposição para a relação que se traduz nos moldes do amor possível, com maiores chances de felicidade. Disso talvez possa servir de testemunho a insistência de Rosa em colocar-se, diante de seu tradutor, numa relação de relativa 
igualdade, a partir da repetição de formulações como "a nossa tradução", "estamos juntos, nós dois", entre outras.

Vejamos alguns excertos da correspondência que serviram de base a essa visão da relação entre Meyer-Clason e Rosa:

Rosa, 18 de fevereiro de 59: "A tradução e publicação em alemão me entusiasma, por sua alta significação cultural, e porque julgo esse idioma o mais apto a captar e refletir todas as nuances da língua e do pensamento em que tentei vazar os meus livros." (Rosa 2003a: 70)

Meyer-Clason, 13 de maio de 59: "Venho prazerosamente confirmar o recebimento dos seus livros Corpo de Baile e Sagarana [...] Devo confessar que me sinto honrado e feliz de ter encontrado na primeira folha dos respectivos livros a sua tão amável, tão generosa dedicatória. Queira aceitar, pois, minha mais profunda gratidão pela distinção com que me alegrou." (Rosa 2003a: 76)

Rosa, 11 de novembro de 59: "Só hoje me foi possível responder à sua estimada carta de 24 de agosto [...]. E, com sinceridade lhe digo, gostei muito dessas amostras da tradução. Sei das muitas dificuldades que o Amigo encontrou pela frente, e admira-me que se tenha podido sair tão bem da empresa. A correspondência é exata, não há deturpações, as boas soluções são de grande felicidade. Fiquei muito contente. Agradeço-lhe e felicito-o. Naturalmente, ocorre em alguns pontos a necessidade de retoque ou de mais rigorosa acertação, o que seria, aliás, inevitável, dada a própria natureza do texto. Em anexo, relaciono esses pontos, discriminando-os." (Rosa 2003a: 83-84)

Rosa, 12 de dezembro de 62: "A respeito das traduções, francesa e inglesa, creio que não me teria explicado bem, o que agora faço. Achei, apenas, que, em si, o idioma inglês, como o alemão, se presta mais plasticamente à versão de uma linguagem viva e concreta, com suas inovações e rebeldias. [...] O que penso, porém, é que a língua alemã permitirá, seguramente, versão mais bela e completa, cingindo muito mais estreitamente o texto original, e assim não duvido de que suas traduções vão ser as primeiras, as mais vivas." (Rosa 2003a: 95)

Meyer-Clason, 5 de janeiro de 63: "Embora a confiança que o amigo vai depositando na minha fraca força de tradutor de sua obra pese na minha consciência literária, ela também me fortifica e me conforta." (Rosa 2003a: 97)

Rosa,17 de junho de 63: "Naturalmente, eu mesmo reconheço que muitas das ousadias expressionais têm de ser perdidas, em qualquer tradução. [...] E, pensando assim, reconheço também que temos de fazer sacrifícios. Mas, não tanto quanto os que se verificaram na tradução americana. Acho que eles simplificaram demais, em certas passagens. Principalmente, cortaram muita coisa boa e muita coisinha importante." (Rosa 2003a: 113)

Rosa, 13 de janeiro de 64: [Ao receber a notícia de que a tradução de Grande Sertão : Veredas para o alemão estava pronta] "Obrigado. Só com amor, sei, é que uma tarefa dessa se faz." (Rosa 2003a: 130)

Rosa, 9 de abril de 64: "Notícia boa, recebida ontem: o Corpo de baile, na tradução e para a edição italiana, em Mailand (Feltrinelli), JÁ ESTÁ EM MÁQUINA, deve sair em

\footnotetext{
${ }^{3}$ A passagem parece sugerir a opressão exercida por Onís sobre Rosa.
} 
breve. A tradução, do Prof. Edoardo Bizzarri, é perfeita, tadellos e prächtig. [...] Espero, e estou certo, porém, de que a 'nossa' será a tradução número 1, a espetacular e básica." (Rosa 2003a: 180)

Rosa, 9 de fevereiro de 65: “[...] o Corpo de Baile já tem uma tradução básica, 'autorizada', definitiva: a de Bizzarri. O Grande Sertão: Veredas tem também a sua: a de Meyer-Clason. O Sagarana, não. E note, a tradutora dele não é um Tradutor como Meyer-Clason ou Bizzarri, infelizmente." (Rosa 2003a: 236)

Meyer-Clason, 21 de agosto de 67: "Caro Mestre, (Espero que aceite esta minha forma de tratamento [...]). Estou redigindo o meu posfácio para as Primeiras [Estórias]. A fim de poder entrar exatamente no tema da discussão, solicito-lhe ainda algumas palavras para confirmar, refutar ou retificar a seguinte tese referente a como vejo a sua obra [...]." (Rosa 2003a: 410)

\section{Rosa e Bizzarri}

Somos "sócios" [...] Estou, mesmo, gostando deste jogo

(Rosa)

Gosto que não desgoste do jogo

(Bizzarri)

Por fim, vejamos o caso da correspondência com o tradutor italiano, começando por perguntar o que indicaria a pouca variação na modalidade de tratamento que se enxergou nos dois missivistas. É possível que a pouca variação indique que, já desde o início, escritor e tradutor se reconheciam numa relação de pares. Isso porque a leitura das cartas mostrará que escritor e tradutor construirão uma relação de grande intimidade, talvez a mais íntima e afinada das relações de Rosa com um tradutor, a ponto de o escritor, em alguns momentos, equiparar sua atividade à do tradutor, ou, até mesmo, propor a quase inversão dos papéis entre eles, como, por exemplo, quando, em carta de dezembro de 1963, afirma o seguinte:

$\mathrm{Eu}$, quando escrevo um livro, vou fazendo como se o estivesse "traduzindo", de algum alto original, existente alhures, no mundo astral ou no "plano das idéias", dos arquétipos, por exemplo. Nunca sei se estou acertando ou falhando, nessa "tradução". Assim, quando me "re"-traduzem para outro idioma, nunca sei, também, em casos de divergência, se não foi o Tradutor quem, de fato, acertou, restabelecendo a verdade do "original ideal", que eu desvirtuara. (Rosa 2003b: 99, aspas e grifos do autor)

Nesse sentido, a relação de Rosa com Bizzarri parece se construir mais uma vez nos moldes do "amor dom ativo de si": uma relação predominantemente marcada pela suplementaridade, uma relação amorosa determinada por um sujeito que quer amar, mas que também se quer amado e que, por isso, procura respeitar o outro em sua diferença, 
não se projetando sobre ele na forma idealizada de um outro-EU (o que, constituindo-se como uma projeção narcísica, minaria a própria possibilidade de o amante ser amado).

O movimento relacional de Bizzarri em direção a Rosa também parece se construir de forma muito semelhante. Parece-nos interessante comentar que por diversas vezes o amor do tradutor pelo autor se escreve de forma tão intensa que pode sugerir uma percepção daquela modalidade do "amor-paixão" em que o eu se apaga diante de um outro completamente idealizado. Alguns exemplos seriam os momentos em que Bizzarri mimetiza o idioleto roseano, ou quando adere à noção imaginária de que ao traduzir "se transfer[e] por inteiro numa outra personalidade", ou quando se refere ao amigo como "Amigo". Porém, tal percepção a nosso ver se desfaz quando percebemos que essas formas escritas pelo tradutor são também endereçadas a ele pelo outro sujeito amoroso: Rosa agradece e elogia o "mimetismo" através de uma forma igualmente totalizante, por exemplo ao dizer, feliz, coisas como "[n]ada do texto original se evaporou"; também a maiúscula incomum é retribuída quando escreve "Se Você não me traduzisse, nada tinha graça!". Não se poderá supor, inspirados nos jogos amorosos mencionados por Freud, que autor e tradutor estão aí vivendo uma relação lúdica de amor feliz, em que reciprocamente expressam pequenos movimentos mais fortes?

Passemos também neste caso a alguns excertos da correspondência que originaram alguns aspectos atribuídos a essa relação:

Rosa, 5 de outubro de 59: "Aqui estou [...], festiva e sinceramente, para lhe agradecer a forte alegria que me deu, com o envio dos números do 'Progresso Ítalo-Brasileiro' com o nosso 'Duelo'. A tradução - de coração o digo - entusiasmou-me, achei-a admirável. Nem sei, nem pensei que fosse possível um trabalho assim. Nada do texto original se evaporou, nada foi omitido, tudo ficou preservado... e prestigiado!" (Rosa 2003b: 15)

Rosa, 21 de novembro de 62: "Sempre volto a admirar, profundamente grato, sua pasmosa tradução do 'Duelo' - que parece mesmo 'não existir', de tão incrível." (Rosa 2003b: 17)

Bizzarri, 03 de dezembro de 62: "Traduzir é praticar um exercício de estilo, uma pesquisa de interpretação; é, afinal, um ato de amor, pois trata-se de se transferir por inteiro numa outra personalidade.” (Rosa 2003b: 19)

Rosa, 25 de janeiro de 63: "Sério, sincero: sua carta me alegrou, fora da conta. Você me promete o que nem me parecia crível. Agora, se a coisa pega - e porque não haveria de pegar? - sei que as traduções italianas de meus livros poderão ser, de longe, as muito melhores, as 'melhoríssimas'! [...] Fiquemos, porém, desde já, unidos, combinados, inseparados!” (Rosa 2003b: 20-21)

Rosa, 5 de abril de 63: "Lido, agora, em livro, limpo e definitivo, seu texto me parece simplesmente mágico. As palavras ficam tão belas, que fico ansioso por estudar mais o italiano, a fim de segui-las até o lontano. Quanta escolha, quanta vida, quanta sutileza, 
quanta energia. Com a mesma mão com que Você dá pouso a um beija-flor ou acaricia uma borboleta, também pode demolir um búfalo com um murro. Depois, e mais que tudo, eu sinto que há uma correspondência íntima, um tom anímico de família, um parentesco entre nós: eu 'continúo', no texto seu italiano, e, não duvide, em muitas passagens me sinto superado, ultrapassado! [...] E não tenho dúvidas: suas traduções de G. Rosa hão de ser, de longe, as melhoríssimas, batendo todas, sejam as para quaisquer idiomas." (Rosa 2003b: 26)

Bizzarri, 23 de abril de 63: "Semana Santa ajudando, o Correio conseguiu entregar-me sua carta só no dia 16. Li a carta, afobado; rejubilei; xinguei o Correio nacional pela protelação de tanta alegria; voltei, afobadíssimo, a ler a carta. E não posso não agradecer ao Amigo as palavras a respeito daquela minha tradução [...]." (Rosa 2003b: 28)

Rosa,3 de junho de 63: "Se Você não me traduzisse, nada tinha graça!" (Rosa 2003b: 34)

Rosa, 11 de outubro de 63: "Já me vejo, enfim, vantajosamente traduzido. Sem piada, mas sincero: quem quiser realmente ler e entender G. Rosa, depois, terá de ir às edições italianas." (Rosa 2003b: 37)

Bizzarri, 17 de outubro de 63: "Confiava, progredindo na tradução, reduzir o número das 'dúvidas'. Parece que está acontecendo o contrário. [...] Tenho que resumir as forças e ir para frente. Teimosia, talvez, de um tris-tris-tris-etc.-neto dos construtores de aquedutos. [...] Quanto à nossa festinha, se V. não se importar e não houver inconveniência, acharia melhor adiá-la para depois, terminada a tradução; neste período penso que estou sertanejo demais para isso!" (Rosa 2003b: 50-51)

Rosa, 28 de outubro de 63: "Você não é apenas um tradutor. Somos 'sócios', e a invenção e criação devem ser constantes. Com Você não tenho medo de nada! [...] Estou, mesmo, gostando deste jogo" (Rosa 2003b: 51)

Rosa, 6 de novembro de 63: "Tenho recebido já editadas ou ainda datilografadas peças de tradutôres meus, em francês, italiano, inglês, norte-americano, alemão, 'austríaco', espanhol e 'uruguaio/argentino' (platenho); tudo bom, em geral, mas sem transmitir-me essa imediata sensação de invulnerabilidade e plenitude, de façanha acabada e perfeita, ida ao limite - que o que V. escreve me traz." (Rosa 2003b: 61)

Bizzarri, 7 de novembro de 63: "Gosto que não desgoste do jogo.” (Rosa 2003b: 67)

Bizzarri, 21 de novembro de 63: "Recebi, em devido tempo, os esclarecimentos relativos ao $3^{-}$rol de 'dúvidas' e a sua carta, bondosa em excesso. Me deixou até perturbado. Obrigado por tudo; mas deixe de lado, por favor, as apreciações elogiosas sobre o tradutor Bizzarri: me dão complexo de culpa, pensando no que resultará da tradução de Corpo de baile." (Rosa 2003b: 87)

Bizzarri, 3 de dezembro de 63: "De fato, suas últimas cartas, junto com muita alegria, me dão uma espécie de complexo de culpa: eu continuo, surdoso, com perguntinhas miúdas, róis de dúvidas, recenseamento de minhas ignorâncias [...]. V. compreenda, perdoe e continue contando-me tudo o que achar interessante. Não vai ser monólogo, não. A primeira fase do trabalho vai chegando ao fim; a conversa - da poesia - vai se aproximando. E será conversa gostosa [...].” (Rosa 2003b: 97-98)

Rosa, 20 de janeiro de 64: "Lei è il vero diavolo! [...] Você é o homem capaz de traduzir qualquer poesia! [...] Quando terminar - e já está terminando... - esta nossa viagem 
companheira, este dialogar de cartas, a que tão bem me acostumei, a gente vai ter saudades e sentir falta." (Rosa 2003b: 129-133)

Procurando encerrar ou "amarrar" este texto, diríamos que, na medida em que as hipóteses levantadas sejam sustentáveis, as cartas dos três tradutores para o escritor indicariam relações bem distintas: uma auto-projeção tipicamente narcísica e a consequente interdição da relação, como no caso de Onís; uma idealização do escritor e a consequente submissão do tradutor, como no caso de Meyer-Clason; uma "viagem companheira", relação entre sujeitos que, em suas diferenças, se reconhecem como pares, como no caso de Bizzarri.

Já as relações construídas por Rosa na direção de cada um de seus tradutores sugeririam, a nosso ver, uma disposição relativamente regular do escritor, pautada nos termos do que Silveira Jr. chamaria de uma "relação de amor", detalhada na proposição lacaniana do "amor dom de si": uma posição que não é homogênea, linear, unilateral, na medida em que o sujeito ora se impõe, ora cede; aceita o desafio da convivência apesar da assimetria indissolúvel relativamente ao interlocutor. Essa relação se funda no pacto do amor possível e, antes de mais nada, abre espaço para que o outro se apresente em sua alteridade - não por força de um simples gesto de generosidade, mas como a única condição em que se torna possível, para o sujeito, tanto o amar quanto o ser amado.

Assim, partindo dessas hipóteses, talvez possamos afirmar que Rosa traduziria, na sua relação de escritor com seus tradutores, uma concepção de amor que também parece permear sua obra de romancista, fazendo jus a seu epíteto de "autor quase de cor", que lhe atribuiria Benedito Nunes (2006). Na voz do narrador de Grande Sertão : Veredas: “Amor vem de amor” (Rosa 1986: 16); mas se, por um lado, “...amor é a gente querendo achar o que é da gente" (p. 316), por outro lado, "a flor do amor tem muitos nomes" (p. 164). Quando, no viver possível das correspondências, o amor ganha seu dizer, diz "com o amor no fato das palavras." (p. 450)

\section{Referências bibliográficas}

BERMAN, A. A prova do estrangeiro: cultura e tradução na Alemanha romântica [...], tradução de Maria Emília Pereira Chanut. Bauru: EDUSC, 2002.

. Pour une critique des traductions: John Donne. Paris: Éditions Gallimard, 1995. 
CARDOZO, M. "Tradução e o trabalho de relação: notas para uma poiética da tradução". In: PIETROLUONGO, M. A.. (Org.). O trabalho da tradução. Rio de Janeiro: ContraCapa, 2009.

. "Tradução, apropriação e o desafio ético da relação". In: OLIVEIRA, M. C. C. de; LAGE, V. L. C. (Org.). Literatura, crítica, cultura I. 1 ed. Juiz de Fora: Editora UFJF, 2008.

FROTA, M. P. A singularidade na escrita tradutora: linguagem e subjetividade nos estudos da tradução, na linguística e na psicanálise. São Paulo e Campinas: FAPESP e Pontes, 2000.

NUNES, B. "O autor quase de cor: rememorações filosóficas e literárias". In: Cadernos de Literatura Brasileira. São Paulo: Instituto Moreira Salles, n.20 e 21, p.236244, dez 2006.

ROSA, J. G. Grande Sertão : Veredas. 27. ed. Rio de Janeiro: Nova Fronteira, 1986.

João Guimarães Rosa: correspondência com seu tradutor alemão Curt Meyer-Clason (1958-1967), edição, organização e notas Maria Apparecida Faria Marcondes Bussolotti; tradução de Erlon José Paschoal. Rio de Janeiro: Nova Fronteira, Academia Brasileira de Letras e Ed. da UFMG, 2003a.

João Guimarães Rosa: correspondência com seu tradutor italiano Edoardo Bizzarri. 3.ed. Rio de Janeiro: Nova Fronteira, 2003 b.

SILVEIRA JÚNIOR, P. M. da. A tradução - dados para uma abordagem psicanalítica. Colégio Freudiano do Rio de Janeiro: Aoutra, 1983.

VERLANGIERI, I. V. R. J. Guimarães Rosa - correspondência inédita com a tradutora norte-americana Harriet de Onís. Dissertação de Mestrado, sob a orientação de Lenira Marques Covizzi. Curso de Pós-graduação em Letras Estudos Literários da Unesp de Araraquara, 1993, 2 v. 